\title{
Arthropod appendages from the Weeks Formation Konservat-Lagerstätte: new occurrences of anomalocaridids in the Cambrian of Utah, USA
}

\author{
Rudy LeROSEy-Aubril, ThOMAS A. HegnA, LOREN E. BABCOCK, ENRICO BONINO \& CARLO KIER
}

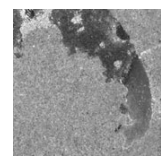

\begin{abstract}
The Guzhangian Weeks Formation (House Range, Utah, USA) contains a virtually unstudied but diverse assemblage of "soft-bodied" organisms. This fauna includes several enigmatic appendages of arthropods that are described in this contribution. Six appendages (two isolated and four paired appendages) are interpreted as frontal appendages of a probably new species of Anomalocaris. They are characterized by a slender morphology, 14 podomeres, ventral spines alternating in size, up to three auxiliary spines per ventral spine, and only two dorsal spines. Another isolated appendage is also tentatively assigned to Anomalocaris, but it exhibits a more robust morphology, a stronger distal tapering, and apparently simple ventral spines, suggesting that it may represent a distinct taxon. These frontal appendages represent the youngest occurrence of anomalocaridids in Laurentia and demonstrate the persistence of older, Burgess Shale-type taxa in the Weeks Formation. An assemblage of four antenniform and six robust and heavily-armed appendages is also described. These are interpreted as the serially arranged, anterior appendages of a single individual of an undetermined arthropod species. This association of three pairs of robust, spiny appendages with two pairs of antenniform structures in a Cambrian arthropod is unique. - Key words: Arthropoda, Anomalocarididae, Weeks Formation, Konservat-Lagerstätte, Cambrian, Guzhangian.
\end{abstract}

\begin{abstract}
Lerosey-Aubril, R., HegnA, T.A., BABCOCK, L.E., Bonino, E. \& KiER, C. 2014. Arthropod appendages from the Weeks Formation Konservat-Lagerstätte: new occurrences of anomalocaridids in the Cambrian of Utah, USA. Bulletin of Geosciences 89(2), 269-282 (5 figures). Czech Geological Survey, Prague. ISSN 1214-1119. Manuscript received April 19, 2013; accepted in revised form September 5, 2013; published online March 4, 2014; issued May 19, 2014.

Rudy Lerosey-Aubril, Laboratoire de géologie de Lyon: Terre, Planètes, Environnement (UMR 5276, CNRS), Université Claude Bernard Lyon I, Campus de la Doua, 2 rue Raphaël Dubois, 69622 Villeurbanne, France; leroseyaubril@gmail.com•Thomas A. Hegna, Department of Geology, Western Illinois University, Tillman Hall 113, 1 University Circle, Macomb, IL 61455, USA; ta-hegna@wiu.edu・Loren E. Babcock, School of Earth Sciences, The Ohio State University, Columbus, Ohio 43210, USA, and Department of Geology, Lund University, Sölvegatan 12, SE-223 62 Lund, Sweden; loren.babcock@geol.lu.se • Enrico Bonino \& Carlo Kier, Back to the Past Museum, Carretera Cancún, Puerto Morelos, Quintana Roo 77580, Mexico; e_bonino@yahoo.it, kierc@cancun.com.mx
\end{abstract}

The Weeks Formation is one of at least nine Cambrian Konservat-Lagerstätten in the Great Basin region (Utah, Nevada, and California) of the western United States (e.g. Gunther \& Gunther 1981, Robison 1991 and references therein, Lieberman 2003, English \& Babcock 2010, Robison \& Babcock 2011). Fossils from the Weeks Formation have been known for more than a century (Walcott 1908a, b) but many remain to be thoroughly studied. Until recently (Adrain et al. 2009, Robison \& Babcock 2011), the trilobite fauna had received little scientific attention since Walcott $(1916 a, b)$, with the exception of a couple of unpublished Ph.D. theses (Beebe 1990, Peters 2003). This trilobite fauna is remarkable for the high proportion of articulated specimens (Adrain et al. 2009, Robison \& Babcock 2011) and for the rare but exquisite preservation of digestive structures (Robison \& Babcock 2011, Lerosey-Aubril et al. 2012). The shelly fauna also includes abundant inarticulate brachiopods (Walcott 1908b, Rowell 1966, Streng \& Holmer 2006), hyolithids (Walcott 1908b), sponge spicules, and rare echinoderms (Ubaghs \& Robison 1985). The upper part of the Weeks Formation has produced a rather diverse assemblage of both weakly-biomineralised and soft-bodied organisms dominated by arthropods and worms (e.g. paleoscolescids). This includes the oldest aglaspidid (LeroseyAubril et al. 2013), the enigmatic aglaspidid-like arthropod Beckwithia (Raasch 1939, Hesselbo 1989), and the arthropod appendages described herein. Although fragmentary, these new fossils give important insights into the composition of the Weeks Formation fauna and its relationships with older, better-known Cambrian soft-bodied assemblages. 


\section{Geological setting}

Cambrian shelf deposits of Laurentia were intermittently characterized by three broad lithofacies belts that encircled the continent (Palmer 1973; Aitken 1978, 1997): an Inner Detrital Belt (IDB), a Middle Carbonate Belt (MCB), and an Outer Detrital Belt. These lithofacies belts are the result of the presence of a carbonate platform (MCB) that separated proximal, largely restricted environments (IDB) from distal, open-marine, and relatively deep-water environments (ODB). In present-day western North America, they extend along a grossly north-south axis, the succession IDB-MCB-ODB being observed from east to west. During Cambrian Epochs 2 and 3, an eastward, fault-controlled trough, termed the House Range Embayment, developed within the carbonate platform in east-central Nevada and west-central Utah (Rees 1986). This led to the local deposition of shales and argillaceous carbonates typical of the ODB, instead of the shallow-water carbonates of the MCB. In the central House Range, such deposits are represented by a continuous sequence encompassing the Wheeler and Marjum Formations and the lower part of the Weeks Formation (Elrick \& Snider 2002, Miller et al. 2012). In contrast, the Orr Formation, which conformably overlies the Weeks Formation, is composed of shallow-water carbonates typical of the MCB lithofacies (Miller et al. 2012). This indicates that the upper part of the Weeks Formation records a substantial shallowing succession (Beebe 1990), which marks the end of the House Range embayment as a locus for deep-water sedimentation (Miller $e t$ al. 2012).

The 300-m-thick sequence of the Weeks Formation is predominantly composed of thin-bedded lime mudstones, wackestones, and grainstones with variable amounts of shale (Beebe 1990). Beds yielding exceptionally preserved arthropods and other fossils are exposed in North Canyon (Weeks Canyon of C.D. Walcott) on the NE slope of Notch (locality 824 in Robison \& Babcock 2011), central House Range, Millard County, Utah. They correspond to the upper part of the Weeks Formation and may therefore represent a relatively shallow-water environment. This is supported by the fact that the non-trilobite arthropod fauna is dominated by aglaspidids or aglaspidid-like arthropods. These organisms mostly occur in proximal, relatively shallow-water deposits (Lerosey-Aubril et al. 2013), such as those of the IDB lithofacies of the St. Lawrence Formation (Furongian) in the Upper Mississippi Valley. However, the trilobite fauna suggests that there was open-marine access during the time of deposition of the Weeks Formation (Robison \& Babcock 2011). According to the developing global chronostratigraphy of the Cambrian (Peng et al. 2009, Babcock et al. 2011), the presence of the polymerid trilobite Cedaria minor and agnostoids indicative of the Proagnostus bulbus Zone (agnostoid zonation) in the upper part of the Weeks Formation indicates a late Guzhangian age for the exceptionally preserved fauna.

\section{Material and methods}

The examination of hundreds of fossil-bearing slabs has revealed three isolated appendages and three assemblages of appendages belonging to arthropods previously unknown from the Weeks Formation. These specimens are deposited in the Back to the Past Museum (Cancún, Mexico; BPM), the Smithsonian Institution, National Museum of Natural History (Washington, USA; USNM), the University of Utah (Salt Lake City, USA; UU), and the Yale Peabody Museum (New Haven, USA; YPM). BPM 1025 represents an assemblage of appendages, USNM 593550 and 593551 (part and counterpart) and UU 13072.02 are pairs of appendages, and UU 13072.01a and UU 13072.01b (part and counterpart), YPM 237023 (part and counterpart) and BPM 1034b are isolated appendages. Both the part and counterpart of YPM 237023 are associated with inarticulate brachiopod fragments. UU 13072.02 is also associated with inarticulate brachiopods and an undetermined fossil (priapulid worm?), whereas the left librigena of an undetermined trilobite occurs close to UU 13072.01a along with a possible, poorly preserved appendage of similar size. Lastly, BPM 1034b is on a slab also bearing nearly complete specimens of the trilobites Lonchocephalus pholus Walcott, 1916a, Menomonia semele (Walcott, 1916a), and Weeksina unispina (Walcott, 1916a) and a couple of inarticulate brachiopods. High-resolution photographs of BPM 1025, BPM 1034b, UU 13072.01a, b, and UU 13072.02 were taken with a digital camera Leica DFC420 mounted on a microscope Leica MZ12.5; except for UU 13072.02, these specimens were immersed in diluted ethanol to enhance the contrast between fossil remains and the matrix.

Figure 1. Photographs of frontal appendages of Anomalocaris aff. canadensis from the Weeks Formation (Cambrian: Guzhangian), North Canyon, House Range, Utah, USA. • A, B - part (USNM 593550) and counterpart (USNM 593551) of a pair of frontal appendages. $\bullet$ C - pair of poorly preserved frontal appendages (UU 13072.02). • D, E - isolated frontal appendage (YPM 237023); D - part, E - counterpart. • F-J - isolated frontal appendage (proximal portion missing) immersed in diluted ethanol; F-H - part (UU 13072.01a), F- general view, G-detail of F, showing the distal part of the appendage, with its dorsal (ds) and terminal (ts) spines, $\mathrm{H}$ - detail of F, showing the ventral spine of P8 and its three auxiliary spines (arrows); I, J - counterpart (UU 13072.01b); I - detail of J, showing the ventral spine of P8 and two of its three auxiliary spines (the most basal one is missing), J - general view. B, E-H are mirrored to facilitate comparisons. 
Rudy Lerosey-Aubril et al. - Cambrian anomalocaridids from Utah

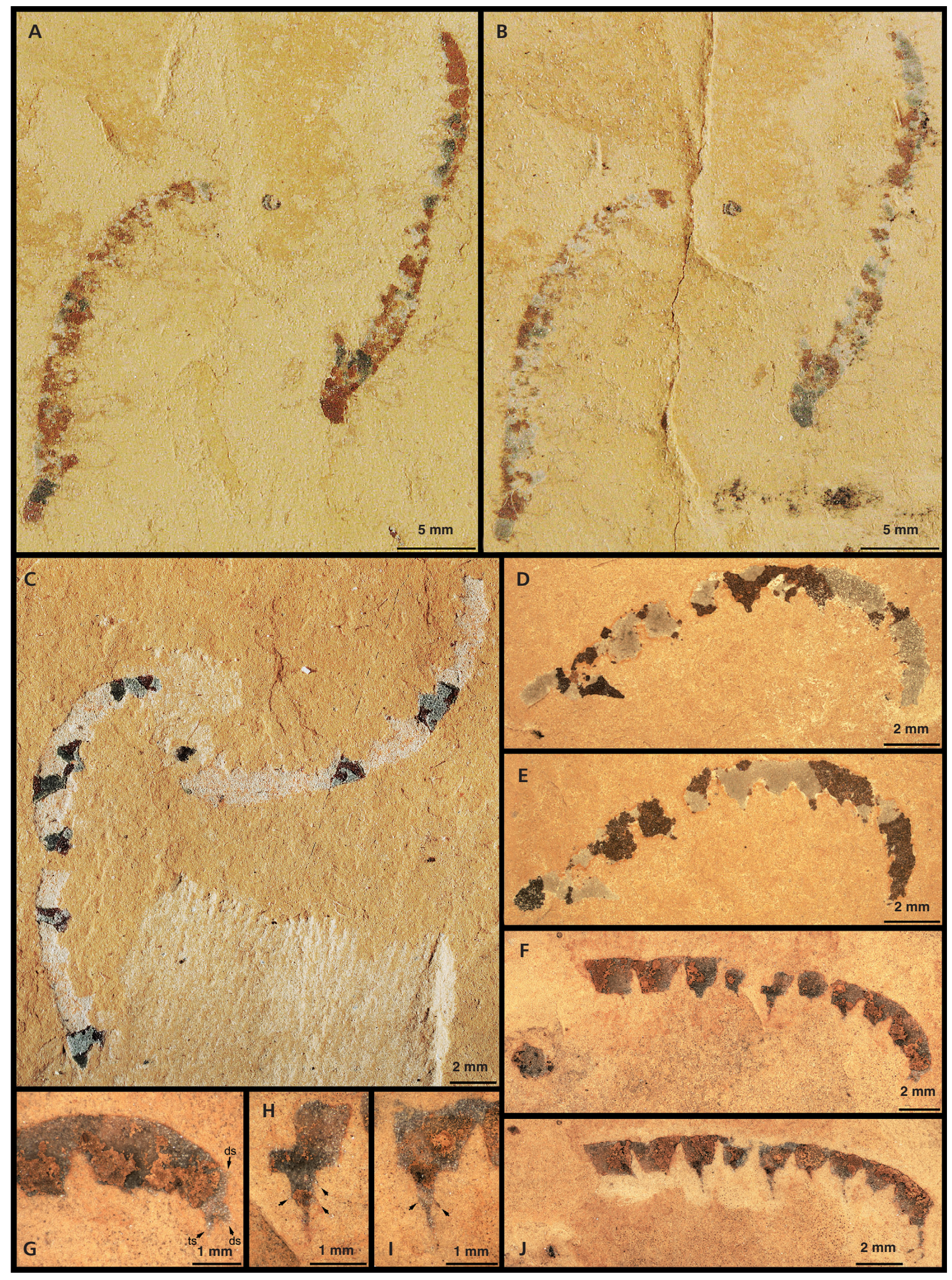


Part and counterpart of YPM 237023 were photographed using a Leica DFC420 camera mounted on a Leica MZ16 microscope, and USNM 593550 and 593551 using a Canon EOS Rebel Xsi digital camera with a Tamron XRDi lens. The photographs were used to make interpretative drawings on Adobe Photoshop CS5. BPM 1025 was also investigated using a scanning electron microscope (SEM; JEOL 310 JSM-6490LV) equipped with an energy dispersive X-ray (EDX) module (EDAX-Ametek). Lengths of the appendages assigned to Anomalocaris aff. canadensis and Anomalocaris? sp. were measured along their mostly smooth margin ("dorsal margin" as defined below).

Terminology and abbreviations. - For the anomalocaridid appendages described herein, we follow Briggs (1979) in using "ventral margin" to refer to the usually concave margin that bears numerous spines (i.e. the "ventral spines"), and "dorsal margin" to refer to the opposite, generally convex margin that bears a few spines (i.e. the "dorsal spines") on distal podomeres only. "Auxiliary spines" refers to small spines located on the lateral margins of a ventral spine, whereas "terminal spines" are spines at the distal tip of the appendage. $\mathrm{P} 1-14$ refer to podomeres 1 to 14 and the numbering reflects a proximal-distal axis.

\section{Preservation}

Shelly remains from the Weeks Formation are usually preserved in their original mineralogy. However, the exoskeletons of trilobites and aglaspidids frequently show evidence of a partial silicification (Beebe 1990, Adrain et al. 2009, Lerosey-Aubril et al. 2013). Internal organs (e.g. digestive structures) are preserved with calcium phosphate (Lerosey-Aubril et al. 2012) or more rarely with iron oxides (unpublished data). Exceptionally preserved organisms are otherwise preserved with iron oxides and/or an undetermined material (likely to be silicate) containing $\mathrm{O}, \mathrm{Si}, \mathrm{Al}$, and $\mathrm{Mg}$.

All the specimens described herein are preserved as nearly two-dimensional compression fossils. EDX analyses performed on BPM 1025 have revealed significant amounts of $\mathrm{O}$ and $\mathrm{Fe}$, suggesting that it is predominantly composed of iron oxides. Small peaks of Ti, Al, Si, and Ca were also present on the spectra. However, as the latter three elements are the most abundant elements in the surrounding matrix, they were probably detected through the thin layer of fossilised material. EDX analyses could not be performed on the other specimens considered herein; nonetheless, they all exhibit the same aforementioned features of Weeks Formation soft-body preservation: a layer of the undetermined greenish/bluish grey material surrounding a layer of iron oxides.

\section{Systematic palaeontology}

Arthropoda von Siebold, 1848 (sensu Legg \& Vannier 2013)

Order Radiodonta Collins, 1996

Family Anomalocarididae Raymond, 1935

\section{Genus Anomalocaris Whiteaves, 1892}

\section{Anomalocaris aff. canadensis Whiteaves, 1892}

Figures 1A-J, 2A-J, 3

Material. - USNM 593550 and 593551, part and counterpart of a pair of appendages; UU 13072.01a, b, part and counterpart of an isolated appendage (proximal portion missing), UU 13072.02, part of a pair of appendages; YPM 237023, part and counterpart of an isolated appendage.

Description. - The six appendages range from ca 20 to $25 \mathrm{~mm}$ in length. They are similar in general morphology, but also in proportions and characteristics of each podomere, which supports their assignment to Anomalocaris aff. canadensis. The appendages are slender, only moderately narrowing distally (Fig. 1). They are all flexed ventrally to some degree, but the flexure may be even along the entire length of the specimen (Fig. 1A, B, appendage on the left) or restricted to the distal portion (e.g. Fig. 1D, E). The distribution of ventral spines, the presence of indentations along the ventral margin and, in some cases, marks on the surface of the fossils suggest that it is composed of 14 podomeres (Fig. 2A-E). The triangular shape of the indentations separating the podomeres (Fig. 1F, J) evocates the putative arthrodial membranes described in other Anomalocaris species (e.g. A. canadensis, Daley \& Edgecombe 2014, fig. 13.2, 3, 5, 7). The non-preservation of

Figure 2. Interpretative drawings of Anomalocaris aff. canadensis from the Weeks Formation (Cambrian: Guzhangian), North Canyon, House Range, Utah, USA. • A, B - part (USNM 593550) and counterpart (USNM 593551) of a pair of frontal appendages. $\bullet$ C - pair of poorly preserved frontal appendages (UU 13072.02). • D, E - isolated frontal appendage (YPM 237023); D - part, E - counterpart. $\bullet$ F-J - isolated frontal appendage (proximal portion missing); F-H - part (UU 13072.01a), F - general view, G - detail of F, showing the distal part of the appendage, with its dorsal and terminal spines, $\mathrm{H}$ - detail of F, showing the ventral spine of P8 and its three auxiliary spines; I, J - counterpart (UU 13072.01b); I - detail of J, showing the ventral spine of P8 and two of its three auxiliary spines (the most basal one is missing), J-general view. B, E-H are mirrored to facilitate comparisons. Abbreviations: as - auxiliary spine, ds - dorsal spine, ts - terminal spine. 
Rudy Lerosey-Aubril et al. • Cambrian anomalocaridids from Utah
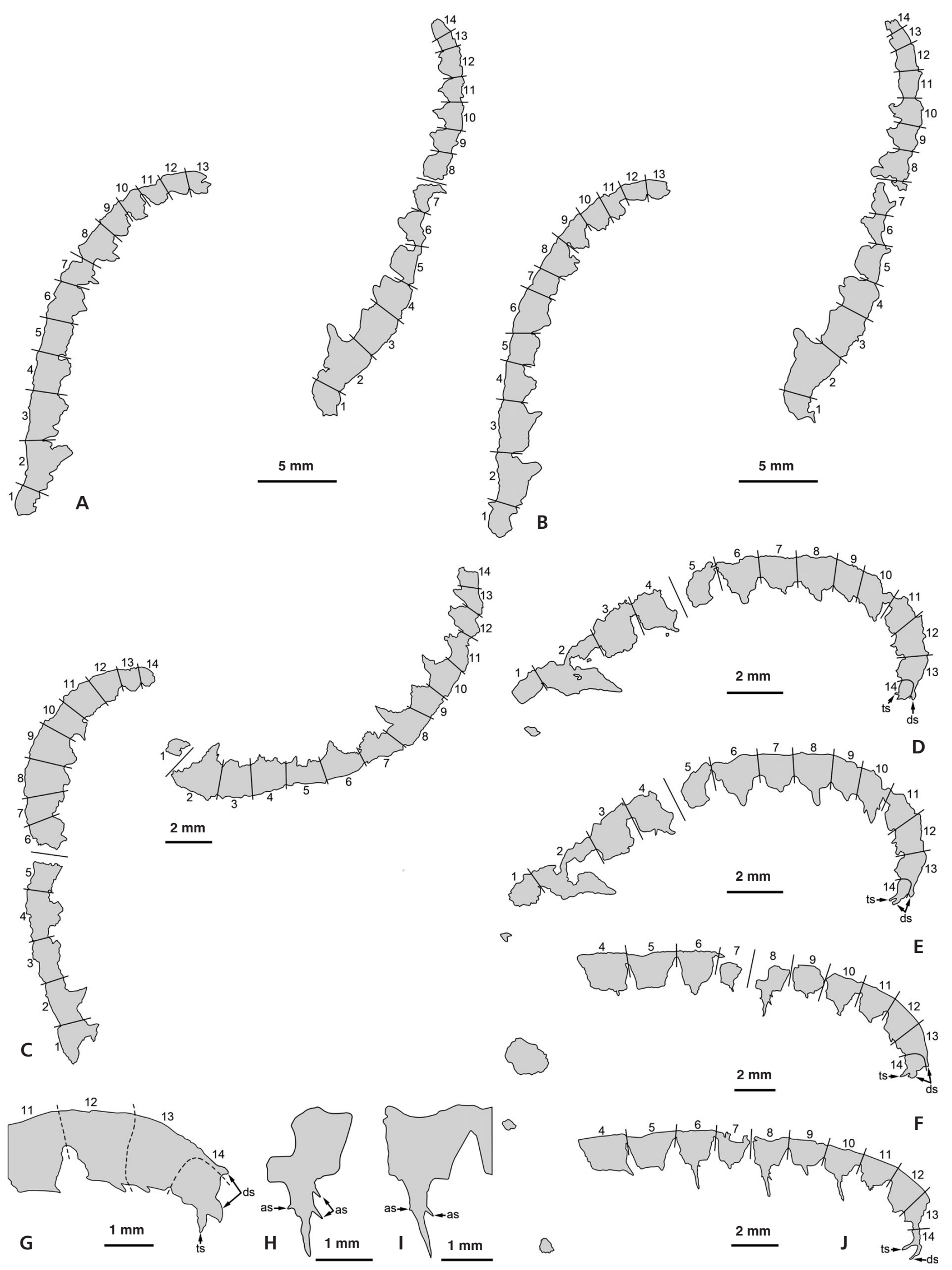


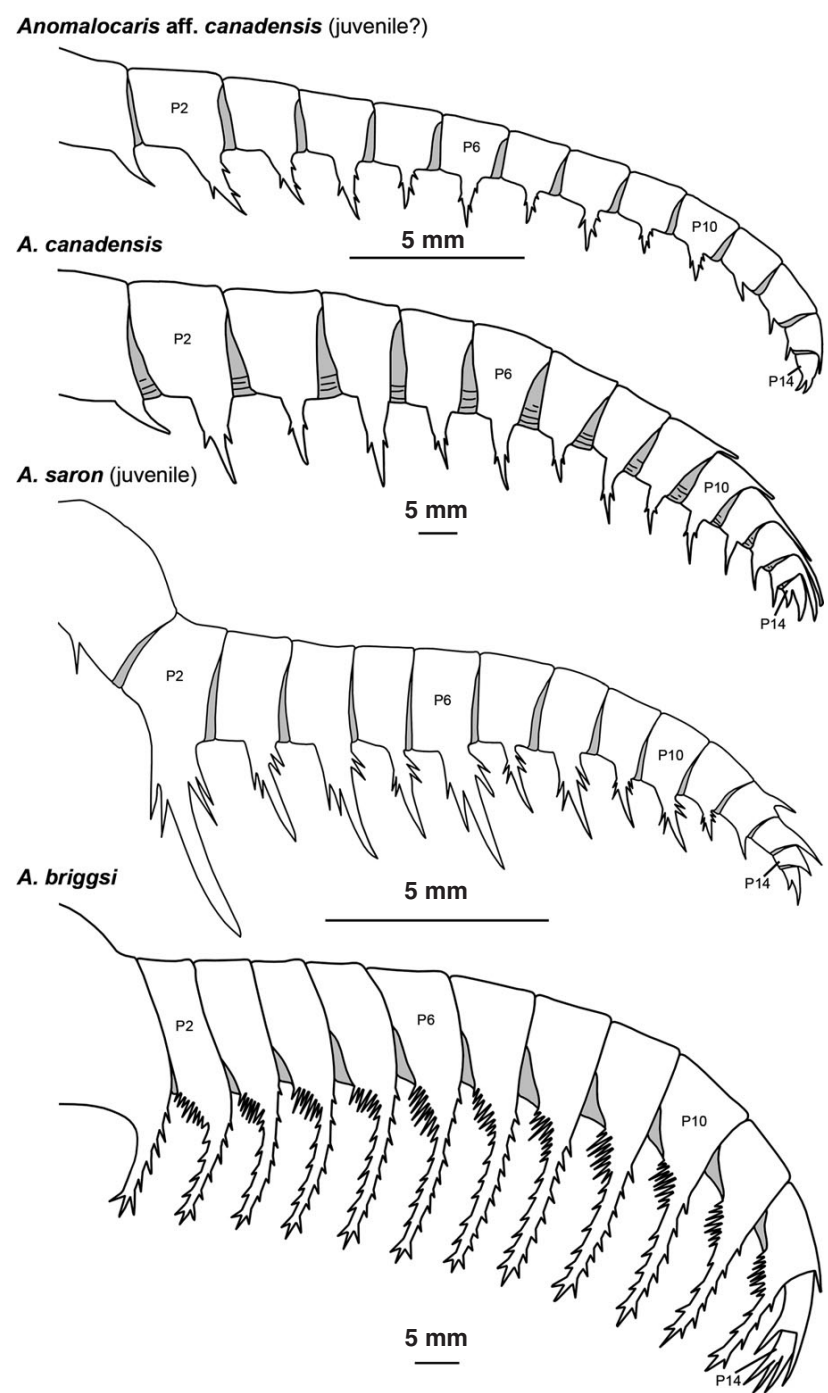

Figure 3. Morphologies of the frontal appendages in four species of Anomalocaris. The frontal appendages of $A$. aff. canadensis are characterized by a particularly slender morphology and the presence of 14 podomeres, dorsal spines on P13 and P14, and three auxiliary spines per ventral spine. This latter characteristic has as-yet been observed on P8 only, but since the type of ventral spines is constant from P2-8 in other species of Anomalocaris, it is assumed to be also the case in this taxon. Frontal appendages also comprise 14 podomeres in A. canadensis, but they more strongly taper distally and they display dorsal spines on P9 to P14 and two auxiliary spines per ventral spine only on P2-10 (proportions based on specimen of fig. 13.6 in Daley \& Edgecombe 2014). With 15, possibly 16 podomeres and two pairs of auxiliary spines per ventral spine on P2-11 (at least), the frontal appendages of $A$. saron are particularly distinctive (reconstruction based on a juvenile specimen illustrated on figs 2B, 3A in Hou et al. 1995). The most conspicuous characteristic of the frontal appendages of $A$. briggsi is the presence of long ventral spines, which are fringed laterally with numerous auxiliary spines on P1-12 (modified after fig. 2 in Daley et al. 2013b).

such structures in the material from the Weeks Formation suggests that they may have been softer than other parts of the appendage, which is to be expected for an articulation zone. The relative proportions of each podomere corres- pond well between all the appendages. P1 is particularly short, but possibly never complete. P2 is the longest of all podomeres. Distally, there is a general trend toward decreasing podomere length, albeit not an absolute trend (e.g. P7 might be shorter than P8, Fig. 2E, J).

A single ventral spine is borne by each podomere from P1 to P13. Ventral spines are always paired in Anomalocaris species, so it seems probable that a second row of ventral spines remained concealed within the matrix in all these specimens. The ventral spine on $\mathrm{P} 1$ is apparently small (Fig. 2C), whereas P2 bears the largest of all (e.g. Fig. 1D). From P2 to P13, the ventral spines alternate in size, with those on the even-numbered podomeres being the largest (Figs 1J, 2J). This pattern is superimposed to a general decrease in size of ventral spines distally. These spines also differ in the way they insert on podomeres and in their orientation relative to them. On P1-5, the ventral spines project distally from the distal half of the podomere at an angle of $\mathrm{ca} 45-50^{\circ}$ (relative to the long axis of the appendage; Figs 1B, D, E, J, 2B, D, E, J). On P6, the ventral spine projects from a point mid-length on the podomere and is orientated at a right angle relative to its margin. More distal ventral spines up to P13 have a similar mid-length insertion on podomeres, but they project at an increasingly low angle relative to podomere margins (Figs 1E, J, 2E, J). Three auxiliary spines are borne by the ventral spine of $\mathrm{P} 8$ in specimen UU 13072.01a (Figs 1F, H, 2F, H), and two of them by the ventral spines of P6 on UU 13072.01b (Figs 1J, 2J) and P10 on YPM 237023 (Figs 1E, 2E). A dorsal spine apparently occurs on P13 and P14. In the latter, it is associated with a terminal spine (Figs 1D-G, J, 2D-G, J). A reconstruction summarizing the main characteristics of the frontal appendages of this species is proposed on Fig. 3.

Discussion. - These appendages are heavily-armed and their different postures indicate some degree of flexibility. Together, these observations are compatible with a grasping function. They also exhibit a number of podomeres and a spinosity pattern that are strongly reminiscent of the frontal appendages of anomalocaridids, specifically those described for species of the genus Anomalocaris (see textfig. 1 in Daley \& Budd, 2010 and Fig. 3). For instance, the frontal appendages of Anomalocaris canadensis Whiteaves, 1892 (e.g. Briggs 1979, Daley \& Edgecombe 2014), A. cf. canadensis (Daley et al. 2013b), and A. pennsylvanica Resser, 1929 (Briggs 1979) possess all 14 podomeres and ventral spines alternating in size, as observed in the appendages from the Weeks Formation. However, the new appendages differ from those of the above mentioned species by the following traits: a particularly slender morphology, with a length (along proximo-distal axis) / height (ventro-distal axis) ratio of most podomeres of 1 or above (e.g. in $\mathrm{P} 2-5$ ), a weak distal tapering, the presence of up to three auxiliary spines on some ventral spines (never more 


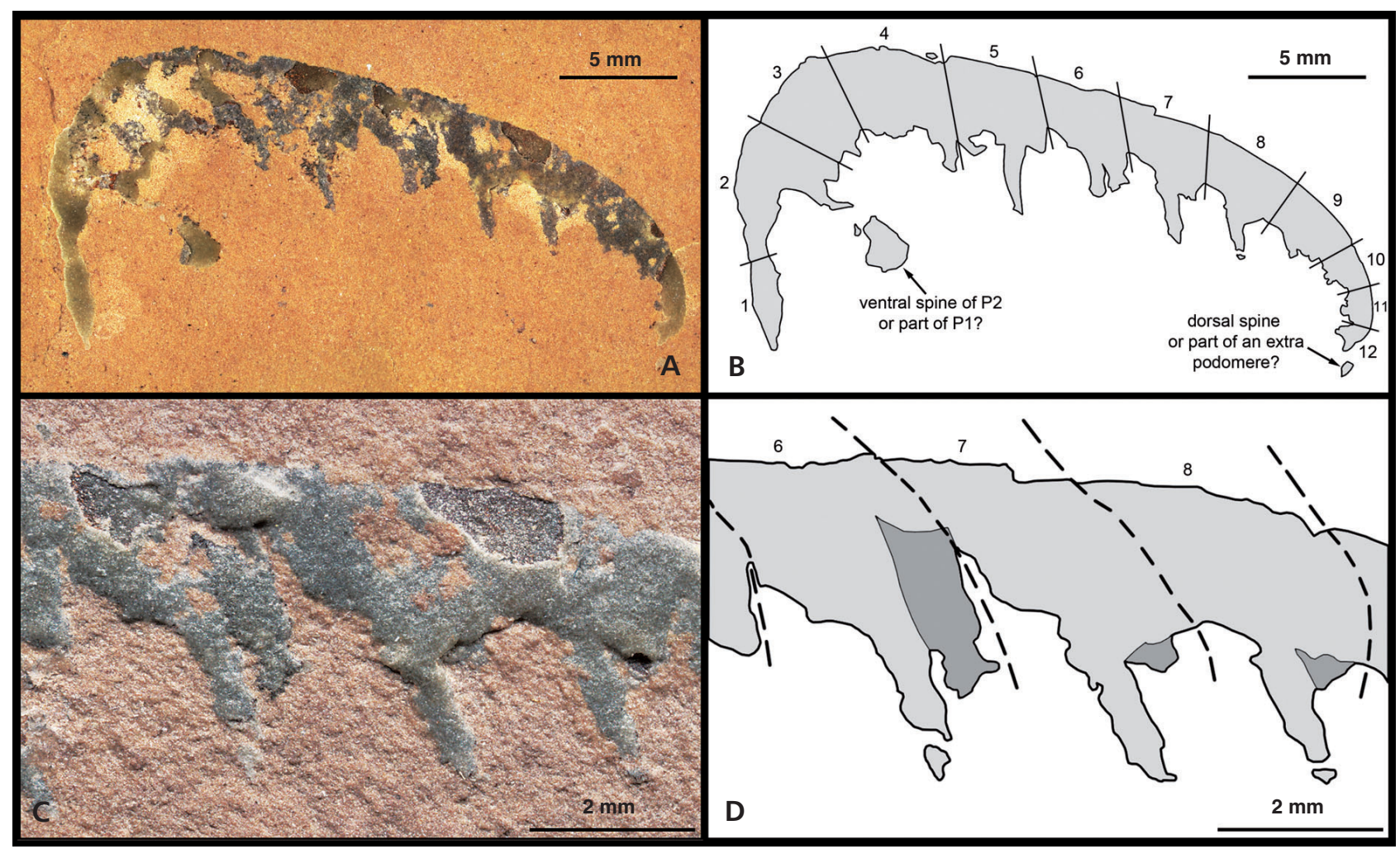

Figure 4. Anomalocaris sp., specimen BPM 1034b, isolated frontal appendage from the Weeks Formation (Cambrian: Guzhangian), North Canyon, House Range, Utah, USA. • A, C - photographs of specimen immersed in diluted ethanol (mirrored); A - general view, C - detail of marginal spines. $-\mathrm{B}, \mathrm{D}$ - interpretative drawings of A and C respectively. For a given podomere, one spine (dark grey) apparently lays on a lower plane than the rest of the fossil (light grey).

than two in A. canadensis, four to six in A. cf. canadensis, and none in A. pennsylvanica) and of dorsal spines on P13 and 14 only (on P9-P14 or P10-P14 in the other species). A rather slender morphology and ventral spines alternating in size are also observed in adult frontal appendages of A. saron Hou, Bergström \& Ahlberg, 1995 from Chengjiang. However, these Chinese frontal appendages differ from those of the Weeks Formation by their higher numbers of podomeres (15, possibly 16), auxiliary spines per ventral spine (4, except in the most proximal pair), and dorsal spines (on P10-15) (Hou et al. 1995). A. briggsi Nedin, 1995 from the Emu Bay Shale possesses frontal appendages with 14 podomeres, but those have a particularly low length/height ratio and their ventral spines have numerous auxiliary spines and do not alternate in length (Daley et al. 2013b), which excludes any close relationships with the frontal appendages of the Weeks Formation.

In summary, these new frontal appendages exhibit characters commonly observed in species of Anomalocaris (14 podomeres, ventral spines alternating in size), along with unique features (high length/height ratios of podomeres, three auxiliary spines on at least some ventral spines, dorsal spines on P13 and P14 only). This suggests that they probably represent a new species within this ge- nus. However, the specimens never exceed $25 \mathrm{~mm}$ in length and it could be argued that their unique traits are related to them belonging to juveniles. Anomalocaridid ontogeny has never been thoroughly explored, but some frontal appendages as small as those from the Weeks Formation are known in A. canadensis (Daley \& Edgecombe 2014), A. pennsylvanica (Briggs 1979), or A. saron (Hou et al. 1995), allowing to comment about ontogenetic changes in these species. In A. canadensis, the number of podomeres and their proportions do not seem to change during ontogeny (Briggs 1979; A. Daley, personal communication 2012). Moreover, no more than a single pair of auxiliary spines per ventral spine has ever been described in this species, whatever the size of the specimens. Comparison between the three known specimens of $A$. pennsylvanica reveals that the length/height ratio of podomeres may slightly decrease and the dorsal spines may become sturdier during the ontogeny of this species (Briggs 1979). In A. saron, the length/height ratio of podomeres may slightly increase during ontogeny, but the most conspicuous differences between small and large specimens concern spinosity. Indeed, a specimen less than two centimeters long illustrated by Hou et al. (1995, fig. 3A) already displays ventral spines with two pairs of auxiliary spines, but these latter 
are located at the base, rather than at mid-length of the ventral spines that consequently look sturdier. Two dorsal spines are also missing in this specimen compared to larger ones, but this might be a preservation bias. The rapid review of the available ontogenetic data on anomalocaridid frontal appendages does not support the hypothesis of juvenile specimens of known species of Anomalocaris being present in the Weeks Formation. Ontogeny might at best explain the fewer number of dorsal spines in the Weeks Formation appendages, but not the particularly high length/height ratio of their podomeres or the presence of up to three auxiliary spines per ventral spine, as opposed to two as in A. canadensis and none in A. pennsylvanica.

To conclude, we believe that these new frontal appendages may or may not have belonged to juveniles, but in any cases they most likely represent a new species of Anomalocaris. However, none of them is sufficiently well-preserved to show all the characteristics of this new taxon and consequently, a formal description should await the discovery of more material, with possibly other body parts. In the meantime, we refer to this taxon as Anomalocaris aff. canadensis, for A. canadensis is the species to which it resembles the most in Laurentia.

\section{Anomalocaris? sp.}

Figure 4

Material. - BPM1034b, an isolated appendage.

Description. - Specimen BPM 1034b represents an isolated grasping appendage of ca $43 \mathrm{~mm}$ in length, which is about four times narrower distally (proximal part of P12) than proximally (distal part of P2; Fig. 4A, B). It is flexed at both extremities, but straight in between. The ventral margin bears remains of robust spines and exhibits indentations, the latter possibly marking the location of nonpreserved arthrodial membranes as in specimens of $A$. aff. canadensis. Added to breaks in slope running from the ventral margin to the dorsal margin, these features allow the tentative recognition of at least 12 podomeres (Fig. 4B). $\mathrm{P} 1$ is only represented by a small patch of fossilized material apparently representing its dorsal part. The length of podomeres does not change substantially from P2-8, but it abruptly decreases from P9 to P12. P5-P8 (at least) were associated with a pair of robust, simple ventral spines. These spines lie almost on the same bedding plane, but this is obviously the result of the flattening of the specimen (Fig. 4C, D; see discussion below). A patch of fossilized material occurs close to $\mathrm{P} 2$ and seems to represent a structure initially connected to this podomere, possibly a large ventral spine (Fig. 4A, B). Alternatively, it may represent the ventral part of $\mathrm{P} 1$, which would be particularly wide in that case. A tiny patch of fossilised material also occurs in the continuity of P12 and could represent a structure projecting from it (e.g. a terminal spine or a dorsal spine) or remain of a more distal podomere (Fig. 4B). Otherwise, there is no evidence of dorsal spines in this specimen.

Discussion. - Like the specimens assigned to Anomalocaris aff. canadensis, BPM 1034b bears strong ventral spines and was probably capable of flexure; this suggests that it was a grasping appendage reminiscent of the frontal appendages of anomalocaridids. However, it is slightly more robust than the frontal appendages described above and clearly tapers distally. There is also no evidence of auxiliary spines in this specimen, despite a better overall preservation, and the ventral spines look sturdier. Whether these differences indicate different affinities or are due to preservation biases is unclear, but we believe this specimen should be described separately.

Careful examination of the topography of the specimen reveals that the two ventral spines associated with each spine-bearing podomere lay on slightly different planes (Fig. 4C, D). Considering the fact that the specimen is strongly compressed, it can be assumed that these spines initially inserted some distance from the plane of symmetry of the appendage, forming two rows along its ventral margin. A similar preservation is sometimes observed with anomalocaridid frontal appendages (e.g. Daley \& Edgecombe 2014, fig. 13). With its strong distal tapering, this appendage resembles frontal appendages of A. canadensis in overall shape. It is composed of twelve podomeres, rather than 14 , but some may actually be missing at both extremities. However, its ventral spines also lack auxiliary spines. Such simple ventral spines occur in A. pennsylvanica, but the frontal appendages in this species are more robust (i.e. lower length/height ratio; see Briggs 1979, text-figs 17-19, pl. 79, figs 4-6) than BPM 1034b. In summary, this specimen differs in several aspects from the frontal appendages described above and can only be tentatively assigned to the genus Anomalocaris.

\section{Class, Order, Family uncertain}

Undetermined arthropod sp. 1

Figure 5

Material. - Specimen BPM 1025, an assemblage of appendages.

Description. - BPM 1025 is made of patches of iron oxides and represents a poorly-preserved assemblage of ten appendages (Fig. 5A, E). The interpretation of this fossil is challenging and requires focusing on some aspects of its morphology in a step-wise sequence. 


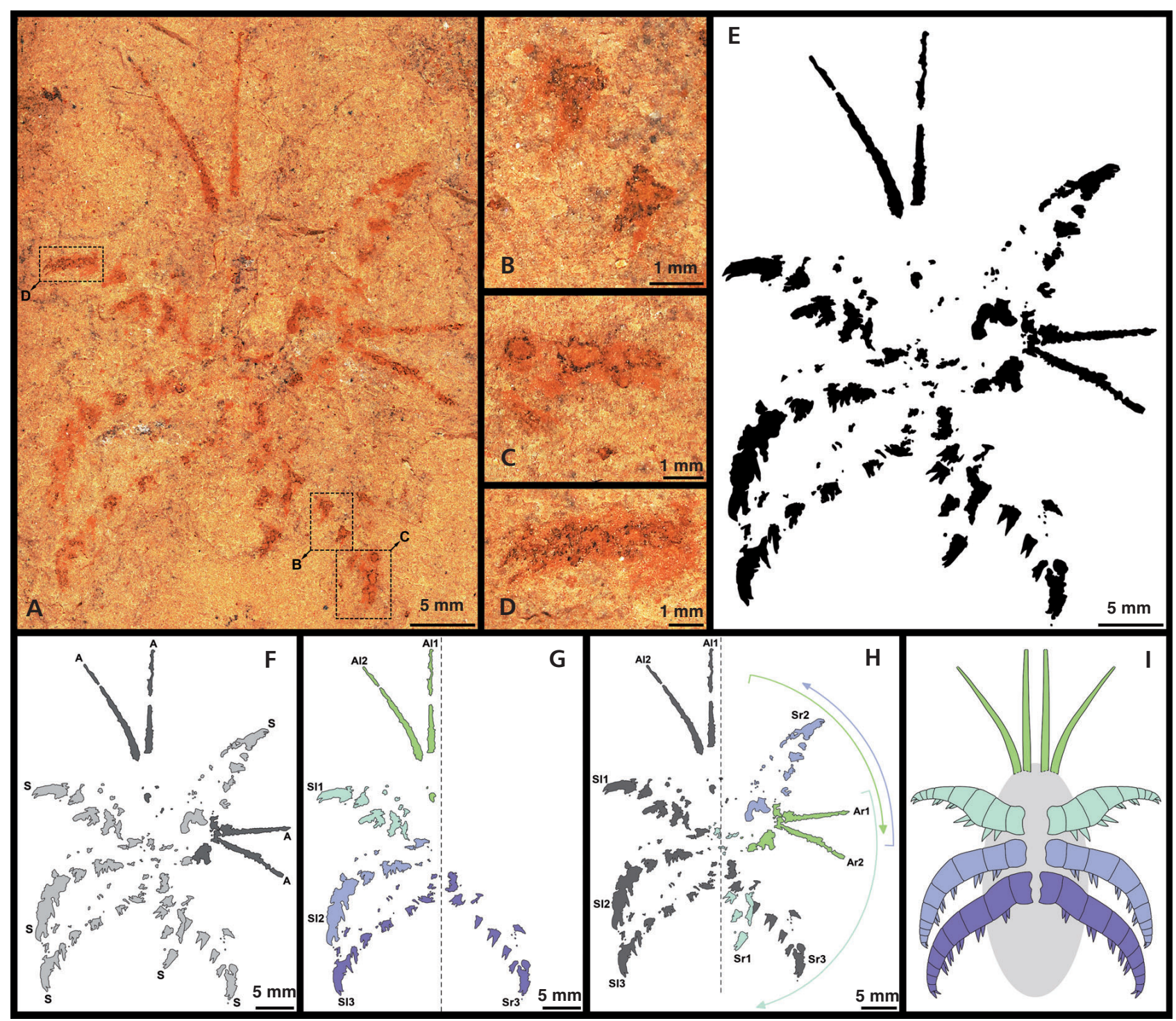

Figure 5. Assemblage of appendages belonging to an enigmatic arthropod from the Weeks Formation (Cambrian: Guzhangian), North Canyon, House Range, Utah, USA. • A-D - photographs of specimen BPM 1025 immersed in diluted ethanol; A - general view, B -two pairs of robust spines along the margin of a spiny appendage; C, D - bifid distal tips of two spiny appendages, probably representing a pair of claws. $\bullet$ E - interpretative drawing of A. $\bullet \mathrm{F}$ - explanatory drawing showing the presence of antenniform (A) and spiny (S) appendages. $\bullet \mathrm{G}-$ explanatory drawing showing the apparently undisturbed series of two antenniform (A11, Al2) and three spiny (S11, S12, S13) appendages on the left side, and the symmetrical disposition of the last pair of spiny appendages $(\mathrm{S} 13, \mathrm{Sr} 3) \cdot \bullet \mathrm{H}$ - explanatory drawing illustrating a possible scenario explaining the arrangement of the appendages on the right by a clockwise rotation of the ensemble composed of $\mathrm{Ar} 1$, Ar2, and $\mathrm{Sr} 1$, and an anticlockwise rotation of $\mathrm{Sr} 2$ after death or ecdysis. $\bullet \mathrm{I}$ - tentative reconstruction of the original disposition of the appendages relative to the body (in grey).

Two types of appendages are recognized. Four of them are antenniform, $c a 9.7-13.7 \mathrm{~mm}$ long, tapering distally, and paired (A on Fig. 5F). Each pair is composed of one appendage gently bending outwards distally and one appendage straight; they apparently represent separate structures, but it cannot be excluded that they were connected to one another proximally, as a single, bifid appendage. Six appendages are heavily-armed (referred to as the spiny type below; S on Fig. 5F). All of them taper distally and bend in the same direction (i.e. the bottom on Fig. 5A). The presence of robust, paired spines along one margin (Fig. 5B) and a pair of smaller spines at the tip is obvious on several of them (Fig. 5C, D). One of these appendages shows that the pairs of robust spines were regularly arranged along the margin, which suggests that it was composed of about eight repeated units (e.g. podomeres of arthropod appendages).

The appendages on the left side of the fossil are regularly arranged without crossing one another, forming what is interpreted as an "undisturbed" series of two 
antenniform appendages and three robust spiny ones (respectively A11, 2 and S11-3 on Fig. 5G). All of them seem to converge medially, likely originating from an unpreserved body. The arrangement of the appendages on the right is more chaotic, but all converge toward the same supposed area of insertion as the left ones. Two are antenniform and three are spiny (respectively Ar1, 2 and Sr1-3 on Fig. 5H), which suggests that their arrangement was similar to that of the left appendages initially. The similar area of insertion and the same number of structures indicate that this assemblage of appendages attached to the same body. This assumption is supported by the symmetrical disposition of S13 and Sr3 (Fig. 5G), which also allows the recognition of a sagittal axis. The positions of Ar1, Ar2, Sr1, and Sr2 are problematic, but they can be explained by post-mortem or post-exuvial, but pre-burial rotations around their insertion sites on the body (Fig. 5H illustrates one possible scenario).

Discussion. -The types of appendages (i.e. antenniform, spiny), their serial arrangement (at least on the left), and especially the fact that they are apparently segmented (at least the spiny ones) strongly suggest arthropod affinities sensu Legg \& Vannier (2013; i.e. segmented invertebrate animal with articulated legs). The apparent displacement of the limbs on the right can be explained by a post-mortem (or post-exuvial) tangling (Fig. 5H). Similar displacements can be observed in modern aquatic environments with either arthropod carcasses that have undergone decay or with molted exoskeletons (RLA, personal observations). Restoration from such taphonomic rotations enables these appendages to be interpreted as belonging to a bilaterally-symmetrical organism. The occurrence of two antenniform appendages and three spiny appendages on each side, the orientation of the spiny ones with their spine-bearing margins facing the same direction (i.e. the bottom of the picture on Fig. 5A, E-H), and the fact that all these appendages apparently inserted in the same area strongly support the view that they all belonged to a single individual (Fig. 5I). However, whether these remains represent the anterior or the posterior part of the body is difficult to ascertain. Antenniform appendages include both antennae and cerci, and therefore may be associated with either end of an arthropod body. The robust, heavily-armed appendages have greater likelihood of being associated with the cephalic region, especially if they were used for seizing or tearing apart prey or carcasses, but it cannot be entirely ruled out that they might have inserted on the posterior part of the body.

Another important question concerns the paired antenniform structures. For a given pair, the two structures seem to have been close to one another proximally, which might indicate that they were elements of a single appendage, such as the flagellum-bearing projections on the great appendages of leanchoiliids. However, a leanchoiliid great appendage comprises three of these flagellum-bearing projections (e.g. Edgecombe et al. 2011), whereas BPM 1025 exhibits only two stout antenniform structures on each side. According to Zhang et al. (2007, figs 34.1, 2, 35.2), the antennae of the Cambrian naroiid Misszhouia is composed of two branches. However, unlike the structures described herein (which are almost identical), the antennal branches of Misszhouia differ markedly in size and morphology - one of them is very short and only composed of three short podomeres. The Devonian crustaceanomorphs Cambronatus brasseli Briggs \& Bartels, 2001 and Eschenbachiellus wuttkensis Briggs \& Bartels, 2001 both have biramous antennae (possibly triramous in the case of E. wuttkensis). Both are very elongate animals with many homonymous limbs, which are difficult to reconcile with the apparent tagmosis of this animal from the Weeks Formation. If the rest of the body were removed, the limb arrangement of the head of E. wuttkensis alone would be rather similar to the unidentified arthropod discussed above - with one pair of biramous antennae and three pairs of robust appendages (Briggs \& Bartels 2001).

In modern crustaceans, bifid first antennae (i.e. antennulae) in adults represent an autapomorphy of the malacostracans (Boxhall 2004, Boxhall \& Jaume 2013). These appendages are composed of a segmented peduncle bearing two multi-annulated flagella that can be very similar from one another. Although considered a derived character within crustaceans (Boxhall 2004, Boxhall \& Jaume 2013), this condition was already acquired in (at least) the Silurian, as illustrated by Cinerocaris magnificus Briggs et al., 2004 from the Herefordshire biota. However, malacostracans, like most crustaceans, also possess biramous second antennae (Boxhall 2004, Boxhall \& Jaume 2013), which is apparently not the case of the arthropod from the Weeks Formation. Double-axis first antennae are also known in remipedes, where they are made of two structures that substantially differ in nature, size, and morphology (Boxhall 2004). One represents the main axis of the antennule; it is segmented and rather long. The second axis is shorter and actually represents a weakly annulated flagellum. Moreover, as in malacostracans, these appendages are followed by biramous second antennae and specialized mandibles (Felgenhauer et al. 1992). There are no evidences of such features in the arthropod from the Weeks Formation, and therefore an assignment to the remipedes is excluded.

The antenniform structures described herein could alternatively represent two pairs of uniramous antennae. To our knowledge, the only Cambrian arthropod genera that possess two pairs of uniramous cephalic appendages are Branchiocaris (Briggs 1976) and Marrella (e.g. GarcíaBellido \& Collins 2006). In both cases, the appendages of 
the two pairs exhibit notable differences in size, podomere number, and shape, whereas the antenniform structures of the arthropod from the Weeks Formation seem almost identical. Moreover, the more posterior appendages in Branchiocaris and Marrella are biramous and possess particularly frail endopods, which strongly contrasts with the robust and heavily-armed appendages associated with the antenniform structures in the fossil from Utah. Thus, whether these antenniform structures are interpreted as a pair of bifid antennae or two pairs of uniramous appendages, they have apparently no equivalent in Cambrian arthropods.

In summary, the material is too fragmentary to allow a precise identification of this specimen beyond the fact that it most likely represents an arthropod (sensu Legg \& Vannier 2013). However, the association of two pairs of antenniform structures (one pair of bifid antennae or two pairs of uniramous antennae) with (at least) three pairs of robust, heavily-armed ones has apparently no equivalent in Cambrian or Recent arthropods. Accordingly, BPM 1025 is thought to represent either a new taxon or a taxon for which appendage morphology was not known.

\section{Discussion}

The frontal appendages described herein constitute the first evidence of anomalocaridids in the Weeks Formation. In the Great Basin, anomalocaridid remains have been reported from the Spence Shale (Briggs et al. 2008), Wheeler Formation (Briggs \& Robison 1984; Conway Morris \& Robison 1982, 1988), and Marjum Formation (Briggs \& Robison 1984) of Utah, the Pioche Formation (Lieberman 2003, Moore \& Lieberman 2009) and Poleta Formation (English \& Babcock 2010) of Nevada, and the Latham Shale (Briggs \& Mount 1982) and Carrara Formation (Babcock 2003) of eastern California. Most specimens found in the House Range were assigned to Peytoia nathorsti (Walcott 1911) (Wheeler Formation: Conway Morris \& Robison 1982, 1988, Briggs et al. 2008; Marjum Formation: Briggs \& Robison 1984). Briggs et al. (2008) also illustrated an oral cone and an incomplete frontal appendage from the Wheeler Formation, which they did not assign to any particular genus. According to Daley et al. (2013a), the isolated appendage probably belongs to Hurdia. The morphological characteristics of at least one type of frontal appendages found in the upper part of the Weeks Formation strongly suggest that they belong to a species of Anomalocaris, which constitutes the youngest occurrence of this genus. By the same token, this discovery also demonstrates that anomalocaridids were still present in Laurentia during the late Guzhangian.

Relatively little is known about the non-trilobite arthropod fauna from the Weeks Formation, but taxa such as
Beckwithia typa Resser, 1931 (Raasch 1939, Hesselbo 1989) and Tremaglaspis vanroyi Lerosey-Aubril et al., 2013 suggest that its composition may notably differ from those of better-known Cambrian arthropod assemblages. This is further illustrated by the description of specimen BPM 1025, which exhibits an intriguing combination of characters that do not fit with the current definitions of any fossil or modern arthropod taxa. However, the presence in the Weeks Formation of frontal appendages of Anomalocaris, i.e. a typical element of older soft-bodied fauna (e.g. Burgess Shale), speaks to a rather progressive evolution of arthropod communities during the late Cambrian Epoch 3.

\section{Summary}

The arthropod appendages described herein expands our limited knowledge of the non-trilobite fauna from the Weeks Formation. They demonstrate the presence of anomalocaridids in these deposits, the youngest occurrence of the group in Laurentia. This is the first evidence of the persistence in the Weeks Formation of a typical component of older soft-bodied biotas. Although preliminary assigned to Anomalocaris aff. canadensis, six of these appendages may actually represent a new species of this genus, possibly juveniles. Four antenniform appendages and six robust heavily-armed appendages present on one slab are regarded as serially arranged appendages attached to the same body. This animal was an arthropod sensu Legg \& Vannier (2013), but the poor preservation of the fossil does not allow a more precise identification. However, the association of four antenniform structures (antennae/cerci?) and three pairs of appendages bearing robust spines has apparently no equivalent in Cambrian or modern arthropods, which suggests that it represents a new taxon or a previously known taxon for which no data on appendage morphology were known. The discovery of these fossils further demonstrates the singular composition of the non-trilobite arthropod fauna from the Weeks Formation.

\section{Acknowledgements}

Robert R. Gaines (Pomona College) provided valuable assistance on the field and found specimens YPM 237023 and UU 13072.02. Phil Reese found specimens USNM 593550 and 593551, and Richard A. Robison made them available to us. This contribution has greatly benefited from discussions on anomalocaridids with Allison C. Daley (Natural History Museum, London). She and an anonymous colleague also provided useful comments as reviewers. Claudia Franz (Senckenberg Research Institute, Frankfurt am Main) assisted with SEM work. We express our sincere gratitude to all these people and to the editor, Olda Fatka (Charles University), for their precious help. 
RLA is also thankful to Jean Vannier for his continuous support. TAH received support from the WIU Department of Geology Foundation for conference travel and fieldwork. This is a contribution of the ANR project RALI 197 "Rise of Animal Life (Cambrian-Ordovician) - organization and tempo: evidence from exceptionally preserved biota".

\section{References}

Adrain, J.M., Peters, S.E. \& Westrop, S.R. 2009. The Marjuman trilobite Cedarina Lochman: thoracic morphology, systematics, and new species from western Utah and eastern Nevada, USA. Zootaxa 2218, 35-58.

Aitken, J.D. 1978. Revised models for depositional grand cycles, Cambrian of the southern Rocky Mountains. Bulletin of Canadian Petroleum Geology 26, 515-542. DOI 10.4095/209146

AitKen, J.D. 1997. Stratigraphy of the Middle Cambrian platformal succession, southern Rocky Mountains. Bulletin of the Geological Survey of Canada 398, 1-322.

BАвсоск, L.E. 2003. Trilobites in Paleozoic predator-prey systems, and their role in reorganization of early Paleozoic ecosystems, 55-92. In Kelley, P.A., Kowalewski, M. \& Hansen, T.A. (eds) Predator-Prey Interactions in the Fossil Record. Kluwer Academic/Plenum Publishers, New York.

Babcock, L.E., Robison, R.A. \& Peng, S.C. 2011. Cambrian stage and series nomenclature of Laurentia and the developing global chronostratigraphic scale. Museum of Northern Arizona Bulletin 67, 12-26.

BeEBe, M.A. 1990. Trilobite faunas and depositional environments of the Weeks Formation (Cambrian), Utah. 103 pp. $\mathrm{Ph}$.D. thesis, University of Kansas, Lawrence, USA.

Boxhall, G.A. 2004. The evolution of arthropod limbs. Biological Reviews 79, 153-300.

Boxhall, G.A. \& Jaume, D. 2013. Antennules and antennae in the Crustacea, 199-236. In Watling, L. \& Thiel, M. (eds) Natural History of the Crustacea. Volume 1, Functional Morphology and Diversity. Oxford University Press, New York.

BRIGgS, D.E.G. 1976. The arthropod Branchiocaris n. gen., Middle Cambrian, Burgess Shale, British Columbia. Bulletin of the Geological Survey of Canada 264, 1-29.

BRIGGS, D.E.G. 1979. Anomalocaris, the largest known Cambrian arthropod. Palaeontology 22, 631-663.

Briggs, D.E.G. \& BARTEls, C. 2001. New arthropods from the Lower Devonian Hunsrück Slate (Lower Emsian, Rhenish Massif, Western Germany). Palaeontology 44, 275-303. DOI 10.1111/1475-4983.00180

Briggs, D.E.G., Lieberman, B.S., Hendricks, J.R., Halgedahl, S.L. \& JARRARD, R.D. 2008. Middle Cambrian arthropods from Utah. Journal of Paleontology 82, 238-254. DOI 10.1666/06-086.1

BRIGgs, D.E.G. \& Mount, J.D. 1982. The occurrence of the giant arthropod Anomalocaris in the Lower Cambrian of southern
California, and the overall distribution of the genus. Journal of Paleontology 56, 1112-1118.

Briggs, D.E.G. \& RoBison, R.A. 1984. Exceptionally preserved nontrilobite arthropods and Anomalocaris from the Middle Cambrian of Utah. University of Kansas Paleontological Contributions 111, 1-23.

Briggs, D.E.G., Sutton, M.D., Siveter, D.J. \& Siveter, D.J. 2004. A new phyllocarid (Crustacea: Malacostraca) from the Silurian Fossil-Lagerstätte of Herefordshire, UK. Proceedings of the Royal Society B, Biological Sciences 271, 131-138. DOI 10.1098/rspb.2003.2593

Collins, D. 1996. The "evolution" of Anomalocaris and its classification in the arthropod class Dinocarida (nov.) and order Radiodonta (nov.). Journal of Paleontology 70, 280-293.

Conway Morris, S. \& Robison, R.A. 1982. The enigmatic medusoid Peytoia and a comparison of some Cambrian biotas. Journal of Paleontology 56, 116-122.

Conway Morris, S. \& Robison, R.A. 1988. More soft-bodied animals and algae from the Middle Cambrian of Utah and British Columbia. University of Kansas Paleontological Contributions 122, 1-48.

DALEY, A.C. \& BudD, G.E. 2010. New anomalocaridid appendages from the Burgess Shale, Canada. Palaeontology 53, 721-738. DOI 10.1111/j.1475-4983.2010.00955.x

Daley, A.C., Budd, G.E. \& CARon, J.-B. 2013a. Morphology and systematics of the anomalocaridid arthropod Hurdia from the Middle Cambrian of British Columbia and Utah. Journal of Systematic Palaeontology 11(7), 743-787. DOI 10.1080/14772019.2012.732723

Daley, A.C. \& Edgecombe, G.D. 2014. Morphology of Anomalocaris canadensis from the Burgess Shale. Journal of Paleontology 88(1), 68-91. DOI 10.1666/13-067

Daley, A.C., Paterson, J.R., Edgecombe, G.D., GarcíaBELLIDO, D.C. \& JAGO, J.B. 2013b. New anatomical information on Anomalocaris from the Cambrian Emu Bay Shale of South Australia and a reassessment of it inferred predatory habits. Paleontology 56(5), 971-990.

DOI 10.1111/pala.12029

Edgecombe, G.D., García-Bellido, D.C. \& Paterson, J.R. 2011. A new leanchoiliid megacheiran arthropod from the lower Cambrian Emu Bay Shale, South Australia. Acta Palaeontologica Polonica 56, 385-400. DOI 10.4202/app.2010.0080

Elrick, M. \& SNIDER, A.C. 2002. Deep-water stratigraphic cyclicity and carbonate mud mound development in the Middle Cambrian Marjum Formation, House Range, Utah, USA. Sedimentology 49, 1021-1047. DOI 10.1046/j.1365-3091.2002.00488.x

English, A.M. \& BABCOCK, L.E. 2010. Census of the Indian Springs Lagerstätte, Poleta Formation (Cambrian), western Nevada, USA. Palaeogeography, Palaeoclimatology, Palaeoecology 295, 236-244. DOI 10.1016/j.palaeo.2010.05.041

Felgenhauer, B.E., Abele, L.G. \& Felder, D.L. 1992. Remipedia, 225-247. In Harrison, F.W. \& Humes, A.G. (eds) Mi- 
croscopic Anatomy of Invertebrates. Volume 9, Crustacea. Wiley-Liss, New York, Chichester, Weinheim, Brisbane, Singapore, Toronto.

García-Bellido, D. \& Collins, D.H. 2006. A new study of Marrella splendens (Arthropoda, Marrellomorpha) from the Middle Cambrian Burgess Shale, British Columbia, Canada. Canadian Journal of Earth Sciences 43, 721-742. DOI 10.1139/e06-012

García-Bellido, D.C. \& Collins, D. 2007. Reassessment of the genus Leanchoilia (Arthropoda, Arachnomorpha) from the Middle Cambrian Burgess Shale, British Columbia, Canada. Palaeontology 50, 693-709.

DOI 10.1111/j.1475-4983.2007.00649.x

Gunther, L.F. \& Gunther, V. 1981. Some Middle Cambrian fossils of Utah. Brigham Young University Geology Studies 28, $1-87$.

Hesselbo, S.P. 1989. The aglaspidid arthropod Beckwithia from the Cambrian of Utah and Wisconsin. Journal of Paleontology 63, 635-642.

Hou, X., Bergström, J. \& Ahlberg, P. 1995. Anomalocaris and other large animals in the Lower Cambrian Chengjiang Fauna of southwest China. GFF 117, 163-183. DOI 10.1080/11035899509546213

LEGG, D.A. \& VANNIER, J. 2013. The affinities of the cosmopolitan arthropod Isoxys and its implications for the origin of arthropods. Lethaia 46(4), 540-550. DOI 10.1111/let.12032

Lerosey-Aubril, R., Hegna, T.A., Kier, C., Bonino, E., HaberSETZER, J. \& CARRÉ, M. 2012. Controls on gut phosphatisation: the trilobites from the Weeks Formation Lagerstätte (Cambrian; Utah). PLoS ONE 7, e32934.

DOI 10.1371/journal.pone.0032934

Lerosey-Aubril, R., Ortega-Hernández, J., Kier, C. \& Bonino, E. 2013. Occurrence of the Ordovician-type aglaspidid Tremaglaspis in the Cambrian Weeks Formation (Utah, USA). Geological Magazine 150, 945-951.

DOI 10.1017/S001675681300037X

Lieberman, B.S. 2003. A new soft-bodied fauna: the Pioche Formation of Nevada. Journal of Paleontology 77, 674-690. DOI 10.1666/0022-3360(2003)077<0674:ANSFTP>2.0.CO;2

McLaughlin, P.A. 1980. Comparative Morphology of Recent Crustacea. 177 pp. W.H. Freeman and Company, San Francisco.

Miller, J.F., Evans, K.R. \& Dattilo, B.F. 2012. The Great American Carbonate Bank in the miogeocline of western central Utah: tectonic influences on sedimentation, 769-854. In Derby, J.R., Fritz, R., Longacre, S.A., Morgan, W. \& Sternbach, C. (eds) The Great American Carbonate Bank: The Geology and Economic Resources of the Cambro-Ordovician Sauk Sequence of Laurentia. American Association of Petroleum Geologists Memoir 98.

Moore, R.A. \& Lieberman, B.S. 2009. Preservation of early and middle Cambrian soft-bodied arthropods from the Pioche Shale, Nevada, USA. Palaeogeography, Palaeoclimatology, Palaeoecology 277, 57-62.

DOI 10.1016/j.palaeo.2009.02.014
Nedin, C. 1995. The Emu Bay Shale, a Lower Cambrian fossil Lagerstätten, Kangaroo Island, South Australia. Memoirs of the Association of Australasian Palaeontologists 18, 31-40.

Palmer, A.R. 1973. Cambrian trilobites, 3-11. In Hallam, A. (ed.) Atlas of Palaeobiogeography. Elsevier, Amsterdam \& New York.

Peng, S.C., Babcock, L.E., Zuo, J.X., Lin, H.L., Zhu, X.J., Yang, X.F., Robison, R.A., Chi, Y.P., Bagnoli, G. \& Chen, Y. 2009. The Global boundary Stratotype Section and Point (GSSP) of the Guzhangian Stage (Cambrian) in the Wuling Mountains, northwestern Hunan, China. Episodes 32, 41-55.

Peters, S.E. 2003. Evenness, richness and the Cambrian-Paleozoic faunal transition in North America: an assemblage-level perspective. 279 pp. Ph.D. thesis, University of Chicago, Chicago, USA.

RaASCH, G.O. 1939. Cambrian Merostomata. Special Papers of the Geological Society of America 19, 1-146.

RAYMOND, P.E. 1935. Leanchoilia and other Mid-Cambrian Arthropoda. Bulletin of the Museum of Comparative Zoology, Harvard University 76, 205-230.

Resser, C.E. 1929. New Lower and Middle Cambrian Crustacea. Proceedings of the United States National Museum 76, 1-18.

Resser, C.E. 1931. A new Middle Cambrian merostome crustacean. Proceedings of the United States National Museum 79, article 33, 1-4.

ReEs, M.N. 1986. A fault-controlled trough through a carbonate platform: the Middle Cambrian House Range embayment. Bulletin of the Geological Society of America 97, 1054-1069.

DOI 10.1130/0016-7606(1986)97<1054:AFTTAC>2.0.CO;2

RoBIson, R.A. 1991. Middle Cambrian biotic diversity: examples from four Utah lagerstätten, 77-98. In SimonetTA, A. \& ConWAY Morris, S. (eds) The Early Evolution of Metazoa and the Significance of Problematic Taxa. Cambridge University Press, Cambridge.

RoBison, R.A. \& BABCOCK, L.E. 2011. Systematics, paleobiology, and taphonomy of some exceptionally preserved trilobites from Cambrian Lagerstätten of Utah. Paleontological Contributions 5, 1-47.

Rowell, A.J. 1966. Revision of some Cambrian and Ordovician inarticulate brachiopods. University of Kansas Paleontological Contributions 7, 1-36.

SiEBold, C.T. von 1848. Lehrbuch der vergleichenden Anatomie der Wirbellosen Thiere. Erster Theil, 1-679. In Siebold, C.T. vON \& STANnius, H. (eds) Lehrbuch der vergleichenden Anatomie. Verlag von Veit \& Company, Berlin.

Streng, M. \& Holmer, L.E. 2006. New and poorly known acrotretid brachiopods (class Lingulata) from the Cedaria-Crepicephalus zone (late Middle Cambrian) of the Great Basin, USA. Geobios 39, 125-153.

DOI 10.1016/j.geobios.2004.10.004

UbAGhs, G. \& Robison, R.A. 1985. A new homoiostelean and a new eocrinoid from the Middle Cambrian of Utah. The 
University of Kansas Paleontological Contributions 115, $1-24$.

Walcott, C.D. 1908a. Cambrian Geology and Paleontology, I. No. 1 - Nomenclature of some Cambrian Cordilleran formations. Smithsonian Miscellaneous Collections 53, 1-12.

Walcotт, C.D. 1908b. Cambrian Geology and Paleontology, I. No. 5 - Cambrian sections of the Cordilleran area. Smithsonian Miscellaneous Collections 53, 167-230.

Walcott, C.D. 1911. Cambrian Geology and Paleontology, II. No. 3 - Middle Cambrian holothurians and medusae. Smithsonian Miscellaneous Collections 57, 41-68.

WalcotT, C.D. 1916a. Cambrian Geology and Paleontology, III.
No. 3 - Cambrian trilobites. Smithsonian Miscellaneous Collections 64, 157-258.

WalcotT, C.D. 1916b. Cambrian Geology and Paleontology, III. No. 5 - Cambrian trilobites. Smithsonian Miscellaneous Collections 64, 303-456.

Whiteaves, J.F. 1892. Description of a new genus and species of phyllocarid Crustacea from the Middle Cambrian of Mount Stephen, B.C. Canadian Record of Science 5, 205-208.

Zhang, X.L., Shu, D.G. \& ERwin, D.H. 2007. Cambrian naraoiids (Arthropoda): morphology, ontogeny, systematics, and evolutionary relationships. Journal of Paleontology 81 (No. sp. 68), $1-52$. 